\title{
Tensiones de un retorno: La Contraofensiva Estratégica Montonera de 1979 y 1980 en Argentina
}

\author{
Tensions in a return: Montonero's strategic counter-offensive \\ of 1979 and 1980 in Argentina
}

Hernán Eduardo Confino*

\begin{abstract}
Resumen
Este artículo se propone, a partir del análisis de las entrevistas a los protagonistas de la Contraofensiva Estratégica Montonera compiladas en el archivo "Memoria Abierta", abordar las tensiones que esas memorias contienen en tanto relatos que se superponen conflictivamente en la tarea de dotar de sentido la experiencia de la CE. Así, en su doble condición de objeto de estudio y fuente histórica, los testimonios se convierten en un terreno fértil para rastrear la lógica que operó detrás de los actos de quienes regresaron al país a luchar contra la dictadura militar en 1979 y 1980.
\end{abstract}

Palabras Clave: montoneros, contraofensiva estratégica, militancia, experiencia, memoria

\begin{abstract}
By analysing the interviews with the protagonist of the "Montonero's strategic counter-offensive" compiled in the 'Memoria Abierta' archive, this article intends to address the tensions that those memories contain as conflictive narratives that signify the "counter-offensive" experience. Thus, in its double condition of objects of study and historical sources, the testimonies become a fertile ground to trace the logic operating behind the acts of those who returned to the country to fight against the military dictatorship in 1979 and 1980.
\end{abstract}

Keywords: montoneros - strategic counter-offensive - militancy - experience memory

\footnotetext{
Argentino, Profesor de Historia (Universidad de Buenos Aires -UBA) y actualmente doctorando en Historia por el Instituto de Altos Estudios Sociales (IDAES) de la Universidad Nacional de San Martín (UNSAM), con sede en el Instituto de Historia Argentina y Americana "Dr. Emilio Ravignani", con Beca Interna Doctoral del Consejo Nacional Investigaciones Científicas y Técnicas (CONICET). Este artículo es un avance de su tesis doctoral que versa sobre la Contraofensiva Estratégica Montonera, dirigida por el Doctor Federico Lorenz. Dirección de correo electrónico: hernan_confino@hotmail.com

Agradezco los comentarios recibidos a una versión previa de este trabajo en la reunión del Núcleo de Historia Reciente de IDAES/UNSAM, coordinado por las Dras. Marina Franco, Paula Canelo y Valeria Manzano. También quiero agradecer las lecturas y comentarios de Andrés Gattinoni, Julián Delgado y Rodrigo González Tizón. Por último, deseo agradecer a los evaluadores anónimos designados por la Revista Izquierdas por sus pertinentes aportes críticos. Naturalmente, ninguno de ellos es responsable de los posibles errores u omisiones en los que haya incurrido el autor.
} 


\section{Introducción}

Producto de la intensificación represiva que se extendió en Argentina desde la plena vigencia del terrorismo estatal a partir del golpe de Estado de 1976, Montoneros decidió el traslado de sus principales cuadros al exterior: la llamada "Retirada Estratégica". Según el clásico estudio de Gillespie:

Los Montoneros sobrevivieron a su pesadilla de 1976-1977 gracias a la gran fuerza numérica que habían logrado a fines de 1975, a la evacuación de sus líderes y a su solidez económica. En el extranjero -en Madrid, Ciudad de México, Roma, París, Caracas y otras capitales- pudieron reagruparse más de 1000 militantes y, posiblemente, por algún tiempo atrajeron hacia ellos a otros exiliados. (Gillespie, 1998: $305)$.

La historia de la organización, sin embargo, llevaba ya una década. En ese tiempo, Montoneros no se había mantenido estático. Al contrario, en consonancia con el devenir histórico, pretendió transformarse a sí mismo casi con igual ímpetu con el que intentó modificar las condiciones que lo rodeaban. Desde sus primeros años como células aisladas (Campos, 2016; Lanusse, 2007) hasta el abandono de la lucha armada entrada la década del ochenta (Gillespie, 1998), la organización revolucionaria fue variando su fisonomía y transformando su estrategia de intervención política en la arena pública. Así, supo autodenominarse organización político-militar y partido revolucionario, organización de masas y, luego, de vanguardia; así, también, alternó estrategias de lucha tan disímiles como, por un lado, la "guerra integral", propiciada por Juan Domingo Perón, en la que se ubicó como "formación especial" del movimiento peronista y, por el otro lado, años más tarde, la "insurrección popular armada" en la que se autorrepresentaba, muerto Perón, como la vanguardia capaz de dirigir la lucha política del campo popular contra la última dictadura militar ${ }^{1}$.

No es la intención de este escrito profundizar en los cambios fisonómicos y estratégicos de Montoneros durante su existencia, sino situar las características de la organización para el momento histórico de la Contraofensiva Estratégica (CE) y problematizar, a través de entrevistas realizadas a sus protagonistas, las motivaciones y sentidos políticos que constituyeron sus experiencias militantes durante la CE. En 1979, Montoneros había adoptado el carácter de Partido Revolucionario de Vanguardia -si bien continuaban

1 En efecto, Montoneros se orientó entre fines de los sesenta y principios de los setenta a quebrar la proscripción que pesaba sobre el Partido Justicialista y su líder, Juan D. Perón. Para ello, alternó estrategias políticas con militares. Entre las primeras, participó en la campaña "Luche y vuelve" y también llevó adelante una estrategia electoralista de cara a los comicios de 1973. Sin embargo, luego de la muerte de Perón y de la represión que se desató contra la organización, Montoneros decidió autoclandestinizarse en septiembre de 1974 y actuar militarmente. Cuando arreció el golpe de Estado, la represión se intensificó y a finales de 1976 se llevó a cabo la "Retirada Estratégica" en su intento por continuar la lucha desde el exterior. La CE fue el intento de volver a ocupar posiciones políticas concretas en el país. 
existiendo el Movimiento Peronista Montonero $(M P M)^{2}$ y el Ejército Montonero ${ }^{3}$ - y la modalidad política prevista era la conducción de una "insurrección popular armada", vinculada a la acción del movimiento obrero organizado y emparentada con la lectura que realizaba la Conducción Nacional de la organización $(\mathrm{CN})$ sobre la forma que iban cobrando los sucesos revolucionarios acaecidos en Irán y Nicaragua ${ }^{4}$.

Un año antes, en 1978, se había llevado a cabo la reunión del Consejo del MPM y de la CN en Roma, en la que se habían discutido los criterios de implementación y lanzamiento de la CE. La necesidad de dicha medida se sustentaba en dos percepciones que fueron cristalizadas en el Boletín Interno $\mathrm{N}^{\circ} 8^{5}$ de fines de ese año: por un lado, que la Junta Militar gobernante en Argentina poseía una fuerte diferenciación en su interior que era posible potenciar a partir de golpes correctamente asestados a su "centro de gravedad"6. Por el otro, que la lucha organizada de la clase obrera manifestaría una nueva etapa de crecimiento en la arena pública para el año 1979 , que podría ser catalizada ${ }^{7}$ mediante la estrategia montonera.

Así se organizó en el exilio la convocatoria a militantes para retornar a combatir al país. Muchos ya habían participado en el territorio argentino y en la organización, si bien entre los destinatarios del llamado también se encontraban quienes se habían exiliado en 1975, antes del advenimiento de la dictadura ${ }^{8}$. Los campos de entrenamiento localizados en México, el Líbano y Siria oficiaron como lugar de preparación política y militar de quienes tendrían una militancia clandestina en el territorio argentino. Organizados en "Tropas Especiales de Agitación (TEA)", encargadas de realizar interferencias televisivas con proclamas montoneras, y en "Tropas Especiales de Infantería (TEI)", responsables de

"El 20 de abril de 1977 pusieron en marcha un Movimiento Peronista Montonero (MPM) tomando como modelo el Movimiento Peronista, pero incorporándole, además de las tradicionales `ramas', una Rama Agraria y una Rama de Profesionales, Intelectuales y Artistas." (Gillespie, 1998: 296) Pretendía, en este punto, ampliar el espacio político del "montonerismo" con aportes que excedían los que se ubicaban en el aparato militar de la organización.

"En abril de 1976 [...] se reunió en el país el Consejo Nacional de Montoneros. [...] Es en esa reunión de Consejo Nacional donde se resuelve transformar la Organización Político-Militar Montoneros en Partido Montonero y Ejército Montonero.” (Pacheco, 2014: 39)

$4 \quad$ En 1979 triunfaron tanto la Revolución Islámica en Irán, que derrocó al Sha Mohammad Reza Pahlevi, como la llevada adelante por el Frente Sandinista de Liberación Nacional en Nicaragua, que derrocó del poder a la familia Somoza. Montoneros observaba estos dos procesos y pronosticaba un desenlace similar para la situación argentina luego de la realización de la CE.

En el Boletín Interno $\mathrm{N}^{\circ} 8$ se publicó la "Orden General de Campaña de Lanzamiento de la Contraofensiva Popular." (Pacheco, 2014: 302)

6 "Personas e instalaciones clave, cuya destrucción demostraría la vulnerabilidad del régimen y, por ende, estimularía a las masas a poner en práctica diversas formas de resistencia." (Gillespie, 1998: 283)

7 De acuerdo al concepto que se utilice se podría desprender la concepción política que subyacía a la orden de Contraofensiva: en el Boletín Interno $\mathrm{N}^{\circ} 13$ los disidentes que protagonizaron la "Rebelión de los Tenientes" criticaban el verbo "lanzar" sosteniendo que daba cuenta de la estrategia foquista que inspiraba las políticas montoneras. En su visión, una contraofensiva popular no podía ser jamás lanzada por un Partido Revolucionario y sí acompañada, a partir de la efervescencia previa de las masas.

$8 \quad$ Sobre todo los presos que habían quedado a disposición del Poder Ejecutivo Nacional y habían sido conducidos al exilio. 
producir operativos armados contra el gabinete económico del gobierno de facto, se conformaron los grupos que llevarían adelante la CE. Además, regresó una cantidad significativa de cuadros de la organización con tareas de coordinación de políticas sindicales y de prensa, principalmente ${ }^{9}$.

Conceptualizada como una etapa de la "defensiva" del campo popular, pero también como el contraataque necesario si lo que se pretendía era repeler a la dictadura del poder, la CE se configuró, hacia el final de la década del setenta, como la receta escogida por Montoneros para acelerar la retirada de la Junta Militar de la conducción del país.

II

En el marco del desarrollo de los estudios sobre el pasado reciente argentino que tuvo lugar en los últimos quince años, la historia de Montoneros ha sido objeto de numerosas investigaciones y aproximaciones, tanto en el campo académico como fuera de él. Sin embargo, ninguna producción académica ha tomado a la CE de 1979 y 1980 como objeto de estudio (Calveiro, 2005; Campos, 2016; Gillespie, 1998; Lanusse, 2005; Longoni, 2007; Lorenz, 2013; Novaro y Palermo, 2003; Salcedo, 2011 y Vezzetti, 2010, entre otros). Sí, en cambio, ha sido abordada desde el registro testimonial y autobiográfico (Astiz, 2005; Bonasso, 1994 y 2010; Gasparini, 2005, 2007; Levenson, 2000; Perdía, 1997, 2013 у Vaca Narvaja, 2002, entre otros), y el registro periodístico (Giussani, 1984; Caballero y Larraquy, 2000; Larraquy, 2006 y Zuker, 2010, entre otros). No obstante, esas intervenciones están enfocadas fundamentalmente en la crónica antes que en el análisis que aquí se pretende realizar.

Este artículo se propone dialogar tangencialmente con diversos núcleos de producción: fundamentalmente, las investigaciones históricas sobre Montoneros en sentido amplio y las intervenciones periodísticas y testimoniales sobre la militancia de la década del setenta. En el primer grupo de trabajos se encuentran las investigaciones propias del registro académico que, a partir de diversos enfoques, reconstruyen la trayectoria de Montoneros (Campos, 2016; Gillespie, 1998, Lanusse, 2005; Salcedo, 2011 y Slipak, 2015). A diferencia de estos trabajos, que han priorizado en su reconstrucción el período previo a la Dictadura Militar (1976-1983) señalando muchas veces a 1976 -momento del golpe de Estado- como una cesura, este trabajo se propone indagar en los últimos años de la década, momento de realización de la $\mathrm{CE}$.

Desde el registro periodístico, se ha abordado la $\mathrm{CE}$ como un hecho que demuestra la culminación de la orientación militar en la forma de hacer política en Montoneros (Larraquy, 2006 y Zuker, 2010). A su vez, en los registros testimonial y autobiográfico, se ubican las diversas reconstrucciones sobre la militancia montonera realizada por ex militantes-combatientes y jefes montoneros (Astiz, 2005; Chaves y Lewinger, 1999;

La CE se desarrolló en dos oleadas en 1979 y 1980, respectivamente. Para la primera oleada se organizó a los grupos en TEA y TEI, pero para la segunda oleada, en 1980, se abandonaron las prácticas militares, y con ellas los grupos de infantería, en pos de una estrategia netamente política (Larraquy, 2011). 
Gasparini, 2005 y 2007; Levenson, 2000; Falcone, 2001 y Perdía, 1997 y 2013, entre otros), y, dentro de ellas, las que particularmente han hecho hincapié en la Contraofensiva Montonera y en sus implicaciones políticas (Astiz, 2005 y Falcone, 2001). En el campo académico, en cambio, la CE no ha sido objeto privilegiado de estudio.

III

A partir del análisis de las entrevistas a los protagonistas de la CE compiladas en el archivo "Memoria Abierta", este artículo se propone abordar las tensiones que esas memorias expresan en tanto relatos que se superponen conflictivamente en la tarea de dotar de sentido la experiencia de la CE. Así, en su doble condición de objeto de estudio y fuente histórica, los testimonios se convierten en un terreno fértil para rastrear la lógica que sustentó los actos de quienes fueron tildados, en ese momento y en las décadas siguientes, como "mesiánicos", "locos" y "militaristas" por sus detractores (Caletti, 2009; Calveiro, 2005; Casullo, 2009; Gago, 2012; Gasparini, 2008) o, mínimamente, fueron invisibilizados por los resultados políticos negativos que cosechó la CE.

Esta invisibilización se ha observado, también, en la falta de interés -como se ha puntualizado anteriormente- que ha suscitado el estudio de la CE por parte de la disciplina histórica, que ha repercutido, entre otras cosas, en el desconocimiento que aún hoy pesa sobre la identidad y el número de los militantes que participaron efectivamente de la maniobra. Otra hipótesis acerca de este vacío historiográfico podría indicar que, antes que desinterés, lo que envuelve a los sucesos de la CE es un tabú y una condena, producto del enfoque que utiliza los resultados políticos que obtuvo como explicación suficiente del proceso histórico (Calveiro, 2005; Gillespie, 1998). En este sentido, la palabra de los protagonistas puede configurarse como una forma adecuada para adentrarse en las motivaciones políticas de quienes expresaron su acuerdo o desacuerdo con el lanzamiento del retorno.

Este escrito pretende, a partir del análisis de las reelaboraciones de los protagonistas de la $\mathrm{CE}$, re-visibilizar los múltiples y conflictivos sentidos políticos de las acciones que se acometieron en el marco de la operación de retorno. Se busca, principalmente, restituir la historicidad de los últimos años de la organización a partir del relato de las experiencias de los militantes que fueron convocados a retornar a proseguir la lucha en Argentina. En dichas experiencias se configura como central la tensión entre los mandatos de la organización que habrían interpelado al grueso de la militancia y la singularidad de su apropiación expresada en las diversas experiencias que sus militantes transitaron. En esta

10 Memoria Abierta es un archivo audiovisual coordinado por Organismos de DDHH, ubicado en el Espacio de Promoción de los DDHH en la ex Esma. Contiene aproximadamente setecientas entrevistas a militantes de la generación del setenta. En este artículo se utilizarán las entrevistas que abordan la CE: las Juan Salinas, Jorge Bernetti, Ernesto Jauretche, Susana Brardinelli, Elvio Alberione, Daniel Cabezas, Nilo Torrejón, Adolfo Bergerot, Gloria Canteloro, Susana Muñoz, Ernesto Villanueva, Oscar Galante y Liliana Mazure. Para mayor información sobre la constitución del archivo audiovisual véase Vera Carnovale, Federico Lorenz y Roberto Pittaluga (comps.) "Memoria y política en la situación de entrevista. En torno a la constitución de un archivo oral sobre el Terrorismo de Estado en la Argentina" en Historia, memoria y fuentes orales, Buenos Aires, Cedinci Editores, 2006. También véase, www.memoriaabierta.org.ar. 
tensión irresoluble entre la pertenencia colectiva y la elección personal se inscribe la posibilidad de inquirir en los motivos que esgrimen quienes participaron del proyecto montonero: seguramente, de tal empresa surjan nuevas preguntas que permitan una aproximación analítica a la CE vehiculizada, fundamentalmente, a partir de la reconstrucción de las experiencias de sus integrantes.

Haciendo foco en las explicaciones y argumentaciones vertidas a propósito de su participación o no en la $\mathrm{CE}$, se pretenden restituir los sentidos políticos de las acciones de los militantes montoneros en los últimos años de la década del setenta y poner en primer plano las experiencias de los protagonistas ${ }^{11}$. Así, se hará hincapié tanto en las reelaboraciones acerca de los condicionantes que pueden haber influido en la decisión de participar en la maniobra, como en la naturaleza del vínculo de los militantes con el proyecto montonero. Lo que se persigue es la posibilidad de visibilizar los valores que sustentaron los motivos sobre los que se fundaron las representaciones, los discursos y las prácticas de los protagonistas para, de esta manera, inquirir sobre sus experiencias e historizar sus acciones. ${ }^{12}$

\title{
Volver $¿$ sin la frente marchita?
}

\author{
"Era una locura. Si vos no estabas en el microclima de la orga era un \\ delirio, era una visión totalmente demencial" ${ }^{\prime \prime}$. \\ "Entonces llevar a la gente a esta situación era un verdadero disparate, \\ se veía lo que iba a pasar y pasó lo que se veía que iba a pasar"14.
}

11 En este punto es necesario hacer una aclaración de orden epistemológico, tendiente a explicitar y poner en relación las dos temporalidades que intervienen en la elaboración de los testimonios. Por un lado, a partir del análisis de las entrevistas, es posible acceder a la subjetividad del presente de la enunciación de los ex militantes montoneros, en este caso en particular, comprendido entre los años 2001 y 2011. Por el otro, y mediada por esta primera, asoman vestigios de la experiencia militante del pasado aquí escrutado que se constituye como un referente de la elaboración memorialística posterior. Si bien el acto de recordación comporta una construcción, dicha construcción no se realiza sobre el vacío. Sobre la importancia de la "subjetividad" como materia de investigación historiográfica ver infra.

12 Como sostiene la historiadora Vera Carnovale en su texto "Aportes y problemas en la reconstrucción del pasado reciente en la Argentina": "La subjetividad se vuelve una dimensión de análisis en sí misma y desde el punto de vista historiográfico nos plantea la pregunta y el desafío de determinar el lugar que ella ocupa en los procesos históricos. ¿De qué manera específica intervienen las subjetividades de los hombres y mujeres comunes en el acontecer histórico? ¿Por qué ante un mismo contexto, ante las mismas condiciones económico-sociales y aún ante un mismo horizonte de sentidos y expectativas las personas toman decisiones diferentes? ¿Cómo confluyen y articulan cada una de esas decisiones en el devenir histórico? ¿Qué nos pueden decir ellas de los colectivos más generales de los que los sujetos forman parte?" Son estas preguntas, entre otras, las que vuelven pertinente un escrito como el que aquí se propone para inquirir sobre los últimos años del proyecto montonero. En este escrito se abordará la subjetividad a través de su dimensión diacrónica, esto es, considerando las experiencias de los hombres y mujeres que participaron de la CE.

13 Memoria Abierta, Testimonio de Juan Salinas, Buenos Aires, 6 y 11 de diciembre de 2002.

14 Memoria Abierta, Testimonio de Jorge Bernetti, Buenos Aires, 13 de octubre de 2001. 
"Locura", "delirio", "demencia", "disparate" son algunas de las representaciones que tiñen la evocación de gran cantidad de ex militantes montoneros al referirse a la CE. Principalmente de quienes prefirieron no retornar pero, de forma paradójica, también de algunos que efectivamente regresaron y sufrieron una derrota sin atenuantes. Es, seguramente, la imagen imperecedera de ese saldo final la que desborda cualquier recuerdo de esa experiencia, pero también la que encorseta dicha rememoración detrás del resultado político, haciendo poca justicia a la complejidad del contexto histórico de los tardíos setentas.

La derrota, siempre presente en las rememoraciones, se configura como el ingrediente fundamental a partir del cual los testimoniantes reconstruyen la maniobra. Es la omnipresencia de dicho resultado la que parecería oscurecer o, peor aún, descartar la necesidad de comprender el proceso que derivó en el lanzamiento de la CE y, también, la $\mathrm{CE}$ propiamente dicha. Antes bien, suele partirse de su resultado político como principio explicativo absoluto y autosuficiente.

Incluso en aquellos recuerdos montoneros -a veces esgrimidos por los mismos sujetos que apelan también a los designios irracionales- que intentan no situarse de lleno en el plano sentimental y ensayar un balance a partir de fundamentos estratégico-políticos, la derrota es una referencia de la cual no logran abstraerse:

\begin{abstract}
Ahora, una vez que uno va a la violencia, y plantea la política en términos de guerra no se puede dar el lujo de perder, porque es perder la política. Haber perdido ahí en términos militares significa que la Argentina sea hoy lo que es. Perdimos la política. ${ }^{15}$

Es difícil creer en una $\mathrm{CE}$ en términos militares si no está precedido de una situación desde un cierto empate, ¿no? ¿Qué es CE? [...] es un momento en el que se da una situación de equilibrio y para romper el equilibrio...no había equilibrio, estábamos perdiendo por goleada. ${ }^{16}$
\end{abstract}

Entre fines de 1978 y principios de 1979 Montoneros había comenzado con el reclutamiento de los militantes requeridos para llevar adelante la operación de retorno, anunciada desde hacía por lo menos dos años, con el inicio de la "Resistencia" y la estrategia de "defensa activa" llevada a cabo a partir de 1976 (Gillespie, 1998; Pacheco, 2014). Dicha convocatoria tuvo como contexto prevalente el exilio, donde se encontraba la mayoría de los sobrevivientes del peronismo revolucionario. Sin embargo, las conceptualizaciones de la militancia montonera estuvieron lejos de ser unánimes con respecto a la posibilidad del retorno a Argentina:

15 Memoria Abierta, Testimonio de Ernesto Jauretche, Buenos Aires, 13 y 17 de diciembre de 2002.

16 Memoria Abierta, Testimonio de Ernesto Villanueva, Buenos Aires, 26 de noviembre y 10 de diciembre de 2002. 
Mirá, de la CE hay un hijoputa (sic) que no lo quiero ni mencionar que anda dando vueltas por ahí. Yo llego a Madrid a verlo al 'Pato Varieté' y a otros compañeros que están vivos y que ahora son funcionarios del gobierno de la ciudad y me acuerdo que viene uno y me dice: 'Pájaro, tenés que volver, porque hay que volver a luchar a la Argentina', y yo le digo 'No, no, yo me fui de la orga, no estoy más'. 'Pero no importa, tenés que ingresar para volver a la contraofensiva', y no volvió, este hijo de puta no volvió, mandó como a veinticinco al frente ${ }^{17}$.

Tal como lo enseña el testimonio de Juan Salinas, exiliado durante el terror estatal en España y apartado de Montoneros, la cuestión del retorno al país se configuró como un tópico polémico entre la militancia peronista revolucionaria en el exterior desde el mismo momento en que se planteó. Salinas juzga moralmente a quien promocionó el retorno al combate pero se abstuvo de llevarlo a la práctica.

Nilo Torrejón, mendocino oriundo de San Rafael, se exilió en Suecia en noviembre de 1979, luego de haber permanecido detenido desde 1976. Desde allí, decidió integrarse a la segunda oleada de la CE, a realizarse en 1980:

después la segunda [CE], que yo estaba allá [Suecia], charlo con un compañero que era gobernador de Santa Fe y soy el único que me vengo (sic), los otros no, me peleé con todos, fue tan malo porque afuera en el ser humano sale toda la porquería: los charlatanes, los palangana, todos los oficiales, todo esto, todo lo otro y cuando hay que ponerla...ya la conocía de adentro de la cárcel, de afuera pero bueno (sic) me ofendí muchísimo, no porque no vinieron, sino porque te mentían: 'volvemos, volvemos todos, y nos vamos, nos vamos' y cuando llegó el momento ninguno se fue"18.

En el testimonio de Torrejón resuenan los ecos de las palabras vertidas por Salinas. La impostura de quienes sostenían la necesidad de retornar a combatir a la Argentina pero que, a fin de cuentas, no lo hicieron. Para Torrejón, esta actitud se encuentra vinculada al modo de ser en el exilio ("afuera en el ser humano sale toda la porquería") y desarrolla una condena moral ("no porque no vinieron, sino porque te mentían") frente a la hipocresía que implicaba sostener la idea del regreso, y desistir a último momento. Una falsedad acentuada por la vigencia de los valores de la política revolucionaria de la época, evidentemente. En sus palabras no hay lugar para los balances netamente estratégico-políticos, antes bien, se enfoca en el comportamiento de los militantes frente a la decisión de retornar como un mandato ético.

Desde una perspectiva análoga, vinculada con los mandatos éticos, la evocación de la experiencia por parte de Gloria Canteloro no contiene, sin embargo, condena alguna. Explica por qué retornó en la primera CE como integrante "miliciana" de los grupos TEI:

17 Memoria Abierta, Testimonio de Juan Salinas, Buenos Aires, 6 y 11 de diciembre de 2002.

18 Memoria Abierta, testimonio de Nilo Torrejón, Mendoza, 15 de Agosto de 2008. 
Volvimos porque había un convencimiento de que era lo correcto, era lo que teníamos que hacer. Nosotros éramos militantes y militantes político-militares, militantes de Montoneros ${ }^{19}$.

En su testimonio no sólo no hay crítica alguna, sino el reclamo de la plena capacidad de decisión que sustentó su retorno para la prosecución de la lucha. El convencimiento al que hace referencia Canteloro parecería estar ausente en la rememoración de Salinas, quien carga las tintas sobre quienes se ocupaban de persuadir a los exiliados de que retornaran clandestinamente a Argentina. En las palabras de Canteloro, en cambio, las convicciones militantes sostenidas en el país no son puestas en entredicho ni por la experiencia carcelaria ni por el exilio.

Similar resulta la rememoración de Susana Brardinelli:

- ¿Al momento que ustedes vuelven me contaste que había habido una ruptura, que había compañeros que no estaban de acuerdo con la política?

Sí, Armando dijo irónicamente 'porque les tocaba a ellos venir ${ }^{20}$.

Armando es Croatto, uno de los cuadros sindicales de mayor envergadura de Montoneros, asesinado durante la CE en septiembre de 1979. La entrevistada es su mujer, Susana Brardinelli quien, nuevamente, y a través de la evocación de la charla con su marido en 1979, pone el foco en la centralidad de volver o no. Desde su punto de vista, las diferencias señaladas por Rodolfo Galimberti, Juan Gelman y compañía habrían estado primordialmente subordinadas al rechazo del retorno a la Argentina antes que a divergencias políticas más profundas con la $\mathrm{CN}^{21}$. La decisión tomada obedecería más a una cuestión emotiva -según la insinuación del testimonio, el miedo o la aversión al regreso ("porque les tocaba a ellos venir"”)- antes que a un balance político de corte racional y estratégico. En la rememoración, la materialidad del retorno se impone como una realidad ineludible, aún más importante que los cálculos políticos que se realizaban desde los diferentes sectores de Montoneros.

Elvio Alberione, en tanto integrante del Consejo del MPM, fue uno de los partícipes de la reunión en Cuba en la cual se discutió la modalidad de la puesta en acto de la CE. Ocupado hasta la fecha del mitín en tareas de integración continental en Panamá, donde trabajaba para la Radio Noticias del Continente ${ }^{22}$, se manifestó en contra de la convocatoria abierta que dispuso la $\mathrm{CN}$ :

19 Memoria Abierta, testimonio de Gloria Canteloro, Rosario, Santa Fé, 11 de Junio de 2010 y 27 de octubre de 2011.

20 Memoria Abierta, Testimonio de Susana Brardinelli, Bernal, Gran Buenos Aires, 4 de noviembre de 2005 .

$21 \quad$ "En febrero de 1979 se produce en el exterior del país un 'pronunciamiento disidente' encabezado por el poeta Juan Gelman y el ex líder de la JP [Juventud Peronista] Rodolfo Galimberti. Cuatro meses después, harán circular un documento público manifestando sus posturas en torno a su alejamiento de Montoneros. [...] Respecto de la Contraofensiva, los 'disidentes' sostienen que no es el hecho de regresar o no regresar al país lo que se tiene que discutir, sino en qué condiciones y para qué se hacía el mencionado retorno." (Pacheco, 2014: 312-316).

22 Radio montonera de onda corta instalada en Costa Rica para evitar la censura de la prensa argentina. 
Lo que sí no me calzaba de ninguna manera era aplicar el concepto de leva. De cualquier manera todos tuvimos responsabilidades de visitar los compañeros, se nos repartió las áreas digamos, en donde se informara esto, de esta decisión de la conducción, pero planteando en términos de casi de (sic) una obligatoriedad ética o moral de incorporarse los que estaban afuera y que tenían una relación orgánica ${ }^{23}$.

Alberione no estaba de acuerdo con la decisión de la $\mathrm{CN}$, pero relata que la suya era una posición muy minoritaria - "casi unipersonal"24- dentro de la reunión del Consejo. Así es que en sus visitas a exiliados respetaba la decisión de quienes no querían retornar:

De manera que eso se consideró como la función mía (sic) en el reclutamiento como, no sé, tal vez hasta como un boicot. Por lo cual se decide que nosotros, sobre la marcha, cuando ya están reingresando, se decide que nosotros también volvamos al país. Tal vez para probar el compromiso con la organización. Sin duda que para algunos debía representar eso $^{25}$.

La cuestión del retorno, si se conceptualizaba como una obligación ética en la leva, también podía convertirse, como la historia de Alberione señala, en un índice de lealtad militante a la organización. Una vez más, el peso específico del regreso se impone por sobre las concepciones estratégico-políticas, relegadas, como mínimo, a un segundo plano. El ser militante se constituye a partir de la lealtad y dicha lealtad se materializa en la acción antes que en el pensamiento. Alberione regresó al país. El sur del Conurbano Bonaerense, su anterior lugar de militancia, se erigió como el teatro de operaciones en el cual se desempeñó como responsable del área política.

Llegado este punto podría intentar establecerse una primera generalización acerca del comportamiento de los altos mandos de la organización con respecto a la participación de los militantes exiliados en la CE. Según los testimonios anteriormente relevados, la CN habría aplicado una convocatoria amplia que habría buscado el enrolamiento de la mayor cantidad de militantes posibles. Sin embargo, el relato de Susana Muñoz matiza lo antedicho y complejiza la trama. Alistada para retornar al país vía Bolivia junto con Daniel Vaca Narvaja, se marchó de Nicaragua (donde estaba colaborando con el Frente Sandinista) en dirección a México para encontrarse con él:

No pasaba nada, no venían a buscarnos, no habían órdenes (sic), y entonces hablé con el Dr. Rodolfo Puiggrós, le pregunté y me dijo 'Montoneros se partió' y entre los que se

\footnotetext{
23 Memoria Abierta, testimonio de Elvio Alberione, Buenos Aires y Córdoba, 7 de Junio y 4 de Agosto de 2008 y 10 de Diciembre de 2009.

24 Ídem.

25 Ídem.
} 
habían ido se había ido Daniel Vaca, así que me había quedado sin compañero de viaje, entonces vino Adriana Lesgart a hablar conmigo y le fui muy sincera con lo del viaje a Bolivia y le dije `disculpáme pero a una compañera que está en las condiciones que estoy yo no le doy ni una máquina de escribir', era un desastre. 'No te preocupes', dijo Adriana, 'te vamos a cuidar' 26

La contención hallada por Muñoz se encuentra a todas luces ausente en los demás testimonios hasta aquí presentados. El caso de Daniel Cabezas, no obstante, es similar a este último. Exiliado en México, se aproximó a Montoneros, donde había militado su hermano desaparecido. Allí se enteró de la caída de su madre, Thelma Jara de Cabezas ${ }^{27}$, situación que precipitó aún más su acercamiento a la organización e intensificó su deseo de regresar al país. Desde Montoneros, y en contra de lo que podría pensarse, no autorizaron su retorno:

Pedí volver lo antes posible, yo quería volver, al margen del análisis que hacía Montoneros de la realidad argentina, yo quería volver, yo pedí volver y al principio me dijeron que no, que hacía falta allá. Volví en una segunda, en la segunda contraofensiva, no en la primera. Yo quería estar acá, ya no tenía sentido para mi estar en México, había que actuar acá. Te estoy hablando de fines del 79 cuando ya había desaparecido mi madre, y ya había aparecido y yo había hecho toda la campaña por mi madre ${ }^{28}$.

Cabezas quería retornar, y finalmente así lo hizo junto a su mujer, Nora Hilb. Pero deseaba volver por motivos exclusivamente personales ("al margen del análisis que hacía Montoneros de la realidad argentina"), los mismos que lo acercaron al MPM durante su exilio mexicano. Aún así, lo que podría pensarse como una decisión motivada a partir de la esfera de los afectos, cobra un nuevo sentido si se tienen en cuenta las características de la moral militante de la época que ciertamente incorporaba la dimensión de la vida íntima como un espacio más de la práctica política (Carnovale, 2011). Sin embargo, en este caso, el desplazamiento resultaba inverso: era la dimensión de la vida íntima la que se derramaba sobre la práctica militante. Finalmente, Montoneros no autorizó su retorno en la primera oleada, pero sí lo hizo en la segunda. Regresó junto a Hilb a realizar trabajos de prensa sin haber recibido instrucción militar alguna. Su caso, como el de Susana Muñoz, alumbra dos cuestiones íntimamente relacionadas: por un lado, que la leva irrestricta a la que aludía Alberione parecería haber sido, en realidad, más selectiva y, por el otro, que los motivos subjetivos del retorno, antes que la evaluación de la línea política emprendida por Montoneros, se constituyeron como un móvil suficiente para abrazar el regreso.

26 Memoria Abierta, testimonio de Susana Muñoz, Mendoza, 2 de Julio de 2007.

27 Thelma Jara, luego de la desaparición de su hijo Gustavo, se desempeñó en la rama femenina de Montoneros. Fue detenida-desaparecida en ESMA, donde fue obligada a posar en un falso reportaje que publicó la Revista Para Ti como parte de la campaña de la dictadura.

$28 \quad$ Memoria Abierta, testimonio de Daniel Cabezas, Buenos Aires, 17 de Abril de 2007. 
El testimonio de Oscar Horacio Galante también tematiza los móviles del retorno. Exiliado en México, hace hincapié en la singularidad de la decisión tomada por cada militante: refiere que cuando se enteró de la CE lo hizo por medio de Federico Frías ${ }^{29}$, quien a la postre fue secuestrado y desaparecido en la segunda maniobra de regreso. Galante comenta que tuvo un intercambio con Frías puesto que estaba en desacuerdo con la participación en la CE, pero

no era que nadie (sic) lo mandaba a la CE, él estaba convencido. Él venía decía (sic) porque las masas están preparadas para la $\mathrm{CE}$ entonces el pueblo se va a organizar y nosotros lo vamos a conducir ${ }^{30}$.

En los fundamentos de la decisión de Frías que reconstruye Galante subyace un análisis político-estratégico, antes que emotivo, aunque involucre activamente la dimensión de la creencia. La pertinencia de la vuelta, siempre desde el testimonio de Galante, obedecía a la posibilidad que tenía Montoneros de conducir al pueblo en una coyuntura que se juzgaba favorable de cara a una insurrección popular armada.

Algo completamente opuesto parecería suceder en el caso de Liliana Mazure. Productora de cine y militante montonera, partió al exilio en 1976 porque, entre otras cosas, ya no era posible, a partir de la imposición de la dictadura militar, exhibir las películas que filmaba con su grupo "Cine Sur". Luego de un paso previo por París, recaló en México en enero de 1977. Allí se integró a la estructura de prensa de Montoneros con un objetivo fundamental: la organización de la campaña de boicot al Campeonato Mundial de Fútbol de la FIFA a realizarse en 1978 en Argentina:

Cuando yo estoy en México el "viejo" Puiggrós sostiene que "Argentina está en una etapa pre-insurreccional, no nos podemos quedar afuera de eso". Lo que yo recibo es ese análisis ${ }^{31}$.

Y con respecto al llamado a la CE sostiene:

Cuando me proponen volver con la CE y yo decido no hacerlo ya no te puedo dar más detalles de cómo aquello se siguió armando porque no lo sabíamos ${ }^{32}$.

A mi fundamentalmente lo que me frena creo que es la obstinación de pensar que lo que yo podía dar era lo que estaba haciendo, que era todo el trabajo en el ámbito cultural $^{33}$.

Mazure, quien luego se integraría a la secesión encabezada por Galimberti, no se enrola en la $\mathrm{CE}$ porque no la siente su ámbito de militancia, pero no realiza un balance acerca de la medida en sí. Luego de rehusarse a participar sostiene que le quedan vedados todos los

29 Participante también del primer regreso, Frías fue llevado a Lima por los militares que lo habían capturado para intentar dar con el Comandante Montonero Roberto Perdía que había instalado su Comando Táctico en esa ciudad (Larraquy, 2006).

$30 \quad$ Memoria Abierta, testimonio de Oscar Galante, Buenos Aires, 5 y 19 de Diciembre de 2007.

31 Memoria Abierta, testimonio de Liliana Mazure, Buenos Aires, 20 y 29 de Junio de 2007.

32 Ídem.

33 Ídem 
detalles del retorno. Sin embargo, al mismo tiempo que ratifica su lugar en el campo cultural, posee un gran respeto por sus compañeros que sí adscribieron a la $\mathrm{CE}$ y prosiguieron con los métodos armados: "tal vez era lo correcto",34.

Si la decisión implicaba volver o no, el caso de Adolfo Bergerot, se ubica ciertamente entre medio de estas dos alternativas claras. Si bien retornó para la primera $\mathrm{CE}$, una vez en el territorio argentino y ante la posibilidad de observar empíricamente lo que los documentos montoneros presentaban en la teoría, decidió desertar:

Tomo la decisión, (...) llego en junio del 79 y nosotros veníamos a la CE donde íbamos a acompañar o a terminar de dar el impulso a la resistencia contra la dictadura y llego en Junio del 79 y que se (sic) estaba celebrando en Buenos Aires, bueno en Argentina, el triunfo, hacía un año que Argentina había salido campeona del mundo del 78, y el juvenil de Japón donde salió Maradona. Argentina estaba de fiesta futbolera y no fue por eso, pero sentí el peso de sentirme un ser extraño, un marciano, intentando llevar adelante una acción política y militar en un país en el (sic) que no quería saber nada ${ }^{35}$.

Bergerot, que había salido del país por estar a disposición del Poder Ejecutivo Nacional, consideró, una vez de vuelta en el territorio argentino encuadrado en un grupo TEI, que no estaban dadas las condiciones para proseguir la lucha en esos términos. Entre los motivos que lo habían llevado a tomar la decisión de retornar, pone en primer plano la sensación de deuda frente a sus compañeros desaparecidos:

Tenía mucho que ver con una cuenta pendiente con los compañeros caídos, es decir, mi retorno en el 79 estuvo marcado claramente por una deuda, una deuda con amigos y compañeros, una deuda, haber sobrevivido al secuestro, a la desaparición me dejaba en deuda con aquellos que no habían podido ${ }^{36}$.

Esa deuda no logra, sin embargo, hacerlo permanecer en el territorio cuando juzga que el sacrificio militante se revela infructuoso frente al contexto político argentino. En su decisión de retorno, de fuerte índole personal, había pesado más el lazo con los compañeros caídos que el acuerdo con la política que impulsaba la organización revolucionaria.

\footnotetext{
$34 \quad$ Ídem.

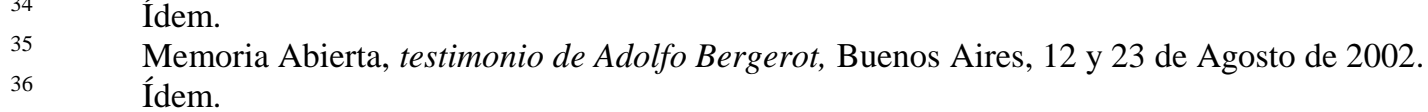

36 Ídem
}

$$
\text { . }
$$




\section{Palabras finales}

A partir de los testimonios analizados se pueden trazar algunos lineamientos parciales. En primer lugar, la convocatoria no funcionó homólogamente en todos los espacios exiliares ni para todos los militantes convocados. Así, entre los testimoniantes observamos casos en los que se rehusaron a regresar (Salinas, Mazure, Galante), pero también otros que resultaron compelidos a hacerlo (Alberione) o que desearon hacerlo merced a acordar con las políticas montoneras (Canteloro) ${ }^{37}$. Estuvieron quienes decidieron retornar y luego desertaron (Bergerot), o quienes, para regresar, tuvieron que lidiar con la negativa de la organización (Cabezas); también aquellos que, a punto de volver, no pudieron hacerlo por cuestiones materiales concretas que excedieron a su voluntad (Muñoz, Torrejón).

En segundo lugar, la pluralidad de argumentos esgrimidos es indicativa de la diversidad de las rememoraciones de los militantes con respecto a los condicionantes que operaron en la decisión del retorno. Solo Canteloro, Frías -en la rememoración de Galante- y Brardinellien su evocación de la charla que mantuvo con Croatto- se muestran receptivos a la política impulsada por Montoneros para 1979. Alberione, quien también efectúa un balance de tinte político-estratégico sobre el lanzamiento de la $\mathrm{CE}$, no coincide con la amplitud de la convocatoria que él, como miembro del Consejo del MPM, debía respaldar y llevar a cabo. $\mathrm{Su}$ retorno al país en tanto militante orgánico ${ }^{38}$ parecería haber sido forzado por la percepción que tuvo la $\mathrm{CN}$ de que estaba boicoteando la realización de la $\mathrm{CE}$ y necesitaba revalidar el compromiso con la organización. Mazure no regresa, en cambio, por considerarse ajena a la lucha armada. Daniel Cabezas y Adolfo Bergerot, por su parte, conceptualizan como secundaria la lectura que se realizaba desde Montoneros sobre la situación política imperante en Argentina, en tanto que el primero ancla su decisión de retorno en su situación familiar, mientras que el segundo lo hace en el vínculo con sus compañeros desaparecidos. Por último, Salinas y Torrejón, aún en desacuerdo con la pertinencia de la CE, manifiestan la condena moral a quienes propagaron su llamado pero luego no lo ratificaron con su participación. Respaldar lo dicho con lo hecho se impone como la lógica de esta argumentación. Una lógica que, evidentemente, apuntalaba la práctica política militante compartida tanto por algunos militantes como por la $\mathrm{CN}$.

La heterogeneidad se impone como el primer saldo de este análisis. Una heterogeneidad que es doble. La primera, concerniente a los diversos posicionamientos que asumen quienes evocan los acontecimientos de los últimos setentas. La otra, su consecuencia inmediata, atinente a los matices que adquiere el objeto de las recordaciones, el pasado montonero y la CE: cómo es visualizado y recordado ese pasado. Aun así, las diferencias aquí analizadas se construyen sobre la base de determinadas percepciones comunes que, de no existir, imposibilitarían cualquier tipo de contraste o comparación. La más importante la configura la relación con el pasado político en revisión. Todos los testimoniantes aquí revistados han

\footnotetext{
37 Canteloro en la entrevista agrega que Manuel Camiño, su pareja se alistó para el retorno en el marco de la CE. Sin embargo, no afinca sus razones en este hecho o, si lo hace, al menos explicita su conformidad con la política montonera.

38 Habría que observar más detenidamente la relación -si es que la hay- entre libertad de decisión y pertenencia orgánica a Montoneros.
} 
sido militantes montoneros y han desarrollado sus experiencias en estrecha relación con el proyecto político sostenido por dicha organización. Sin importar la función, la antigüedad o la responsabilidad, todos han abrazado, en distintas porciones y desde lugares diversos, la identidad política montonera.

Excepto por el testimonio de Juan Salinas, alejado de Montoneros y conforme con la experiencia exiliar en Cataluña, el resto de los testimoniantes reelabora una relación por demás conflictiva con la continuidad de la militancia, con su lugar en el extranjero y con las posibilidades de retorno al país. En sus relatos se percibe el descentramiento espacial ocasionado por la circunstancia del exilio y las ansias de regresar, aunque reelaborados a partir de diversas circunstancias. Cabe destacar que, salvo Elvio Alberione, consejero del MPM, y Gloria Canteloro, retornada en la primera oleada, ninguno de los demás entrevistados esgrime un balance anclado en lo estrictamente político-estratégico. Antes bien, cuando tematizan el regreso, las razones afectivas son las primeras en invocarse: la relación con la militancia revolucionaria, el lazo con los compañeros, con la familia, la ajenidad que supone establecerse fuera del país.

Es el peso específico del retorno el que parecería imponerse sobre las razones políticas que lo justificarían. Como si la decisión hubiera sido pergeñada desde el momento del alejamiento de Argentina, y no a propósito de la propuesta política de contragolpe. Sin embargo, no debe perderse de vista que dicho "subjetivismo" podría ser uno de los efectos del testimonio, producto del tiempo transcurrido entre la recordación y los sucesos recordados (Sarlo, 2005). Máxime cuando la CE dejó detrás de sí una estela de derrota sin precedentes que enseñó el error en el diagnóstico, o mínimamente de su puesta en acto, elaborado por la organización. Aun contemplando esta salvedad, queda a las claras la imbricación entre las dimensiones política y afectiva que horadan las memorias montoneras y que conformaron, también, la práctica militante revolucionaria.

En este sentido, investigar la experiencia del exilio montonero e inquirir sobre el lugar de los militantes dentro de la organización pueden configurarse como pistas para acercarse a las motivaciones que sustentaron el retorno y conformaron sus experiencias. Tanto en la percepción del exilio -y con ello, también, de la ruptura con el mundo militante en la Argentina que le dio origen-, como en la representación de las obligaciones que dependían del lugar ocupado por el militante en la estructura de la organización, pueden hallarse pertinentes antecedentes históricos que permitan inteligir y explicar el curso de la acciones emprendidas posteriormente por los militantes, evitando hacerlo a partir de sus resultados políticos. La consideración de las trayectorias individuales de los militantes que se incorporaron a la operación de retorno, por fin, podría brindar importantes claves explicativas de la experiencia transitada durante la CE y desligarla, finalmente, de los epítetos valorativos que aún hoy obstaculizan su comprensión. 


\section{Bibliografía}

Astiz, Eduardo, Lo que mata de las balas es la velocidad. Una historia de la contraofensiva montonera de 1979, La Plata, De la Campana, 2005.

Bonasso, Miguel, Recuerdo de la muerte, Buenos Aires, Planeta, 1994.

Bonasso, Miguel, Diario de un clandestino, Buenos Aires, Planeta, 2010.

Caballero, Roberto y Larraquy, Marcelo, Galimberti. De Perón a Susana, de Montoneros a la CIA, Buenos Aires, Grupo Editorial Norma, 2000.

Caletti, Rubén Sergio (2009 [1979]) "Focos y vanguardias. Los marxismos que supimos conseguir" en Controversia para el examen de la realidad argentina, Buenos Aires: Ejercitar la Memoria Editores, pp. 18-21.

Calveiro, Pilar, Política y/o violencia. Una aproximación a la guerrilla de los años 70, Buenos Aires, Grupo Editorial Norma, 2005.

Campos, Esteban, Cristianismo y revolución. El origen de Montoneros. Violencia, política y religión en los 60, Buenos Aires, Edhasa, 2016.

$\square$ Carnovale, Vera, Los combatientes. Historia del PRT-ERP, Buenos Aires, Siglo Veintiuno, 2011.

Carnovale, Vera, "Aportes y problemas de los testimonios en la reconstrucción del pasado reciente en la Argentina", en Franco, Marina y Levín, Florencia (comps), Historia Reciente. Perspectivas y desafíos de un campo en construcción, Buenos Aires, Paidós, 2007.

Casullo, Nicolás (2009 [1979]) "La cuestión sindical en la Argentina. Peronismo revolucionario y sindicalismo peronista" en Controversia para el examen de la realidad argentina, Buenos Aires: Ejercitar la Memoria Editores, pp. 21-25.

Chaves, Gonzalo L. y Lewinger, Jorge O., Los del 73. Memoria Montonera, La Plata, De la Campana, 1999.

Falcone, Jorge, Memorial de Guerralarga. Un pibe entre cientos de miles, La Plata, De la Campana, 2001.

Franco, Marina, El exilio. Argentinos en Francia durante la dictadura, Buenos Aires, Siglo Veintiuno, 2008.

$\square$ Franco, Marina, Un enemigo para la nación. Orden interno, violencia y “subversión”, 19731976, Buenos Aires, Fondo de Cultura Económica, 2012.

$\square$ Gago, Verónica, Controversia: una lengua del exilio, Buenos Aires, Biblioteca Nacional, 2012.

$\square$ Gillespie, Richard, Soldados de Perón: los Montoneros, Buenos Aires, Grijalbo, 1998.

$\square$ Giussani, Pablo, Montoneros, la soberbia armada, Buenos Aires, Sudamericana-Planeta, 1984.

$\square$ Jensen, Silvina y Yankelevich, Pablo (comps.), Exilios: destinos y experiencias bajo la dictadura militar, Buenos Aires, Libros del Zorzal, 2007.

$\checkmark$ Lanusse, Lucas, Montoneros. El mito de sus 12 fundadores, Buenos Aires, Vergara, 2007.

Larraqy, Marcelo, Fuimos soldados. Historia secreta de la contraofensiva montonera, Buenos Aires, Aguilar, 2006. 
Levenson, Gregorio, De los bolcheviques a la gesta montonera. Memorias de nuestro siglo, Buenos Aires, Colihue, 2000.

$\square$ Longoni, Ana, Traiciones. La figura del traidor en los relatos acerca de los sobrevivientes de la represión, Buenos Aires, Grupo Norma, 2007.

$\square$ Lorenz, Federico, Algo parecido a la felicidad. Una historia de la lucha de la clase trabajadora durante la década del setenta (1973-1978), Buenos Aires, Edhasa, 2013.

$\square$ Novaro, Marcos y Palermo, Vicente, La dictadura militar (1976-1983). Del golpe de Estado a la restauración democrática, Buenos Aires, Paidós, 2003.

$\square$ Pacheco, Mariano, Montoneros Silvestres (1976-1983). Historias de resistencia a la dictadura en el sur del conurbano, Buenos Aires, Planeta, 2014.

Perdía, Roberto C., La otra historia. Testimonio de un jefe montonero, Buenos Aires, Grupo Ágora, 1997.

$\square$ Perdía, Roberto C., Montoneros. El peronismo combatiente en primera persona, Buenos Aires, Planeta, 2013.

$\square$ Salcedo, Javier, Los Montoneros del barrio, Caseros, EDUNTREF, 2011.

$\square$ Sarlo, Beatriz, Tiempo pasado. Cultura de la memoria y giro subjetivo. Una discusión, Buenos Aires, Siglo Veintiuno, 2005.

$\square$ Slipak, Daniela, Las revistas montoneras. Cómo la organización construyó su identidad a través de sus publicaciones, Buenos Aires, Siglo Veintiuno, 2015.

Vezzetti, Hugo, Sobre la violencia revolucionaria, memorias y olvidos, Buenos Aires, Siglo Veintiuno, 2009.

Yankelevich, Pablo, Ráfagas de un exilio. Argentinos en México, 1974-1983, Buenos Aires, Fondo de Cultura Económica, 2010.

$\square$ Zuker, Cristina, El tren de la victoria. La saga de los Zuker, Buenos Aires, Del Nuevo Extremo, 2010.

Anexo documental

$\square$ Memoria Abierta, testimonio de Elvio Alberione, Buenos Aires, 7 de Junio y 4 de Agosto de 2008 y 10 de Diciembre de 2009.

$\square$ Memoria Abierta, testimonio de Adolfo Bergerot, Buenos Aires, 12 y 23 de Agosto de 2002.

Memoria Abierta, testimonio de Jorge Luis Bernetti, Buenos Aires, 13 de Octubre de 2001.

$\square$ Memoria Abierta, testimonio de Susana Brardinelli, Bernal, Gran Buenos Aires, 4 de Noviembre de 2005.

$\square$ Memoria Abierta, testimonio de Daniel Cabezas, Buenos Aires, 19 de Abril de 2007.

Memoria Abierta, testimonio de Gloria Canteloro, Rosario, Santa Fé, 11 de Junio de 2010 y 27 de Octubre de 2011.

Memoria Abierta, testimonio de Oscar Galante, Buenos Aires, 5 y 19 de Diciembre de 2007.

Memoria Abierta, testimonio de Ernesto Jauretche, Buenos Aires, 13 y 17 de Diciembre de 2002.

Memoria Abierta, testimonio de Liliana Mazure, Buenos Aires, 20 y 29 de Junio de 2007. 
Hernán Confino, Tensiones de un retorno: La Contraofensiva Estratégica Montonera de 1979 y 1980 en Argentina, Izquierdas, 28: 274-291, Julio 2016

$\square$ Memoria Abierta, testimonio de Susana Muñoz, Mendoza, 2 de Julio de 2007.

$\square$ Memoria Abierta, testimonio de Juan Salinas, Buenos Aires, 6 y 11 de Diciembre de 2002.

$\square$ Memoria Abierta, testimonio de Nilo Torrejón, Mendoza, 15 de Agosto de 2008.

$\square$ Memoria Abierta, testimonio de Ernesto Villanueva, Buenos Aires, 26 de noviembre y 10 de diciembre de 2002. 